Peir-An Tsai* and Jyh-Horng Wu

\title{
Influence of tire cord layers and arrangement direction on mechanical properties and vibration isolation of chloroprene rubber composite materials reinforced with polyester tire cord
}

\begin{abstract}
Polyester tire cord is often used as reinforcement in the production of chloroprene rubber (CR) composite materials. This study investigated the influences of polyester tire cord layers and arrangement directions on the mechanical properties and vibration isolation of CR composite materials. The experimental results indicate that the optimal molding condition for bonding tire cord with $\mathrm{CR}$ composites is $170^{\circ} \mathrm{C}$ for $30 \mathrm{~min}$, which enables tire cordreinforced CR composites to exhibit maximum pull-out strength. The compression set, tensile strength, and tear strength of CR composites increased with the increasing number of tire cord layers, and the stretching direction parallel to the arrangement direction of the tire cord produced optimal reinforcement effect. Moreover, the storage modulus of CR composites is better than that of pure CR at low temperature, although it reduced the tan delta at glass transition temperature. Regarding the vibration isolation properties, the transmissibility ratio decreased at resonance frequency, while the damping ratio increased when the $\mathrm{CR}$ is reinforced with increasing number of tire cord layers.
\end{abstract}

Keywords: chloroprene rubber; polyester tire cord; vibration isolation.

DOI 10.1515/secm-2014-0236

Received July 21, 2014; accepted December 23, 2014; previously published online April 17, 2015

\section{Introduction}

Fiber-reinforced rubber composites, which have been extensively developed in recent years, possess characteristics similar to fiber (high strength and high modulus) and

\footnotetext{
*Corresponding author: Peir-An Tsai, General Education Center, JenTeh Junior College of Medicine, Nursing and Management, Miaoli County 35664, Taiwan, e-mail: t920402@yahoo.com.tw Jyh-Horng Wu: Material Application Center, Industrial Technology Research Institute, Tainan 70955, Taiwan
}

rubber matrices (light weight and chemical resistance). Rubber composites primarily consist of a rubber matrix and high-modulus fibers, such as carbon fiber, boron fiber, polyester tire cord, and Kevlar fiber. Fiber-reinforced composites are typically manufactured to form tire cords and fabrics, both of which are then combined with rubber to produce high value-added rubber products.

Polyester tire cord has been widely used in the production of tires, conveyor belts, V-belts, hoses, and big bags. This type of cord provides good strength, fatigue resistance, excellent toughness, dimensional stability, and low-heat generation [1, 2]. Chloroprene rubber (CR) is well known for its high tensile strength [3] as well as resistance to solvents [4], ozone [5], weather [6, 7], oil [8], and heat $[9,10]$.

In our previous study, the optimal vulcanization condition, compression stiffness, dynamic properties, and creep behavior of the tire cord-reinforced CR rubber composite material has been investigated [11]. The objective of the current study was to investigate the optimal bonding conditions, mechanical properties, and vibration isolation of the CR composites reinforced with different numbers of polyester tire cord layers and arrangement directions.

\section{Materials and methods}

\subsection{Materials}

CR (Bayprene 216) was obtained from Lanxess (Germany). Carbon black (N330) was produced by China Synthetic Rubber Co. Ltd. (Taiwan). Zinc oxide (ZnO) and Magnesium oxide ( $\mathrm{MgO})$ were obtain from Yung Chyang Chemical Industries Co. Ltd. (Taiwan). Stearic acid was purchased by KENT Trading Co. Ltd. (Taiwan). Ethylene thiourea, antioxidant D, auxiliary agent (PVI), accelerant agent (DM), dispersing agent and peptizer were obtained from San Wu rubber manufacture Co. Ltd. (Taiwan). Resorcinol formaldehyde latex (RFL)-dipped polyester tire cord [1000/2 denier and twist of 481 (Filament)] provided by San Wu rubber manufacturer 
Table 1: Compositions of CR masterbatch and polyester tire cord.

\begin{tabular}{|c|c|c|c|c|c|c|c|c|c|}
\hline Materials & RF-0 & RF-1 & RF-2 & RF-2-1 & RF-3 & RF-3-1 & RF-4 & RF-4-1 & RF-4-2 \\
\hline \multicolumn{10}{|c|}{ CR masterbatch (unit: phr) } \\
\hline CR & 100 & 100 & 100 & 100 & 100 & 100 & 100 & 100 & 100 \\
\hline Carbon black (N330) & 36 & 36 & 36 & 36 & 36 & 36 & 36 & 36 & 36 \\
\hline $\mathrm{ZnO}$ & 5 & 5 & 5 & 5 & 5 & 5 & 5 & 5 & 5 \\
\hline MgO & 4 & 4 & 4 & 4 & 4 & 4 & 4 & 4 & 4 \\
\hline Stearic acid & 1 & 1 & 1 & 1 & 1 & 1 & 1 & 1 & 1 \\
\hline Ethylene thiourea & 0.5 & 0.5 & 0.5 & 0.5 & 0.5 & 0.5 & 0.5 & 0.5 & 0.5 \\
\hline Antioxidant D & 1 & 1 & 1 & 1 & 1 & 1 & 1 & 1 & 1 \\
\hline Auxiliary agent (PVI) & 0.3 & 0.3 & 0.3 & 0.3 & 0.3 & 0.3 & 0.3 & 0.3 & 0.3 \\
\hline Accelerant agent (DM) & 0.5 & 0.5 & 0.5 & 0.5 & 0.5 & 0.5 & 0.5 & 0.5 & 0.5 \\
\hline Dispersing agent & 0.2 & 0.2 & 0.2 & 0.2 & 0.2 & 0.2 & 0.2 & 0.2 & 0.2 \\
\hline Peptizer & 0.2 & 0.2 & 0.2 & 0.2 & 0.2 & 0.2 & 0.2 & 0.2 & 0.2 \\
\hline \multicolumn{10}{|l|}{ Polyester tire cord } \\
\hline Layers & - & 1 & 2 & 2 & 3 & 3 & 4 & 4 & 4 \\
\hline Arrangement direction & - & {$\left[0^{\circ}\right]$} & {$\left[0^{\circ}, 0^{\circ}\right]$} & {$\left[0^{\circ}, 90^{\circ}\right]$} & {$\left[0^{\circ}, 0^{\circ}, 0^{\circ}\right]$} & {$\left[0^{\circ}, 45^{\circ}, 90^{\circ}\right]$} & {$\left[0^{\circ}, 0^{\circ}, 0^{\circ}, 0^{\circ}\right]$} & {$\left[0^{\circ}, 45^{\circ}, 90^{\circ},-45^{\circ}\right]$} & {$\left[0^{\circ}, 90^{\circ}, 0^{\circ}, 90^{\circ}\right]$} \\
\hline
\end{tabular}

Co. Ltd. (Taiwan). As for the basic recipe, the contents of the CR compound are shown in Table 1.

\subsubsection{Preparation of the CR sheet}

The compounding of $\mathrm{CR}$ with fillers and a dispersing agent was carried out using a Banbury Kneader (SYD-5, Avalong Technology Co. Ltd., Taiwan) with a rotor speed of 40-rev $\min ^{-1}$ for $17 \mathrm{~min}$. Then, the CR was pre-blended with vulcanization ingredients using a laboratory size open two roll mixing mill (TMR-13, size: 8" $\times 20 "$ ", Gang-Jeng Mechanical Industry Co. Ltd., Taiwan) with a friction ratio of 1:1.2 and a nip gap of 0.7-6 mm.

\subsubsection{Preparation of polyester tire cord reinforced with CR composites}

The contents of the sheeted CR masterbatch and polyester tire cord are shown in Table 1 . The CRs vulcanized with and without polyester tire cord were compression molded into test specimens at $170^{\circ} \mathrm{C}$ for $35 \mathrm{~min}$.

\subsection{Characterization}

The pull-out strength was measured using a universal tensile tester (Yang-Yi QC-506, Taiwan) with a tension velocity of $25 \mathrm{~mm} \mathrm{~min}^{-1}$ according to ASTM D4776 specifications. The peel strength of specimens with thermal treatment at $90^{\circ} \mathrm{C}$ for $1-6$ days before testing were measured using a universal tensile tester (Yang-Yi QC-506, Taiwan) with a tension velocity of $25 \mathrm{~mm} \mathrm{~min}^{-1}$ according to ASTM D1876 specifications. The compression set of specimens with a diameter of $29 \pm 0.5 \mathrm{~mm}$ and a thickness of $12 \pm 0.5 \mathrm{~mm}$ under a deformation range of $25 \%$ at $-20^{\circ} \mathrm{C}$, $0^{\circ} \mathrm{C}, 20^{\circ} \mathrm{C}, 45^{\circ} \mathrm{C}$, and $70^{\circ} \mathrm{C}$ for $22 \mathrm{~h}$ were determined using a universal tensile tester (Yang-Yi QC-506, Taiwan), in accordance with ASTM D395 specifications. Tensile strength and tear strength were measured using a universal tensile tester (Yang-Yi QC-506, Taiwan) with a tension velocity of $500 \mathrm{~mm} \mathrm{~min}^{-1}$ according to ASTM D412C and ASTM D642 specifications. (The specimens were sampled in the $0^{\circ}, 45^{\circ}$, and $90^{\circ}$ directions.) Storage modulus and damping factor of the resulting tire cord-reinforced $\mathrm{CR}$ composites were measured using a dynamic mechanical analyzer (DMA, TA Q800). A tension mode testing was applied during the DMA scans, and the scanning range was from $-70^{\circ} \mathrm{C}$ to $50^{\circ} \mathrm{C}$ at a heating rate of $3^{\circ} \mathrm{C} / \mathrm{min}$ and frequency of $1 \mathrm{~Hz}$ under nitrogen atmosphere. The transmissibility ratio $(\mathrm{Tr})$ was measured using a vibration test system (LDS V824LS, UK) with a specimen size of 50 $\mathrm{mm} \times 49 \mathrm{~mm} \times 33 \mathrm{~mm}$ under a load of $1 \mathrm{~kg}$ and frequency of 5-1000 Hz. The definition of the Tr is presented below [12].

$$
f_{0}=\frac{1}{2 \pi} \sqrt{\frac{K g}{W}}
$$

$$
\omega_{0}=2 \omega f_{0}=\sqrt{\frac{K g}{W}}
$$

$$
\operatorname{Tr}=\frac{\sqrt{1+\left(2 \frac{c}{c_{0}} \cdot \frac{\omega}{\omega_{0}}\right)^{2}}}{\sqrt{\left(1-\frac{\omega^{2}}{\omega_{0}}\right)^{2}+\left(2 \frac{c}{c_{0}} \cdot \frac{\omega}{\omega_{0}}\right)^{2}}}
$$


In the equations above, $f_{0}$ is the natural frequency, $K$ is stiffness, $W$ is the load, $\omega_{0}$ is the natural angle frequency, $\omega$ is the vibration angular frequency, $c$ and $c_{0}$ are the viscosity factors (damping factors), and $g$ is the gravitational acceleration.

\section{Results and discussion}

\subsection{Effects of aging and vulcanizing on adhesion between $C R$ and tire cord}

Adhesion between CR and polyester tire cord is crucial in ensuring the overall performance. The rubber-tire cord interfacial adhesion is influenced by the chemical composition of the interfacial layer and processing conditions.

Figures 1 and 2 respectively show the pull-out strength of polyester tire cord-reinforced CR composites at various vulcanization temperatures and vulcanization durations. The experimental results indicate that the optimal molding condition of for bonding tire cord with $\mathrm{CR}$ is $170^{\circ} \mathrm{C}$ for 30 min, which enables tire cord-reinforced CR composites to exhibit maximum pull-out strength. In addition, the pull-out strength of the CR composites increased with the increasing vulcanization duration until $30 \mathrm{~min}$, after which the strength decreased when the duration is beyond $30 \mathrm{~min}$ (Figure 2). Such decrease can be attributed to thermal history accumulation, which causes damage to the bond between the RFL adhesive and the fibers or that between the RFL adhesive and the rubber under high temperature.

Figure 3 shows the peel strength of polyester tire cordreinforced CR composites at $90^{\circ} \mathrm{C}$ for various aging times. As can be seen, the peel strength of polyester tire cordreinforced CR composites increased with aging time. A

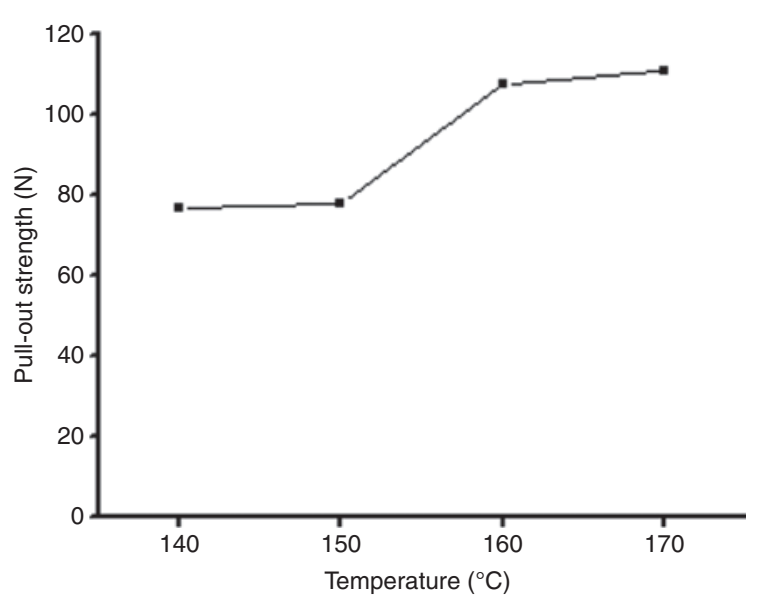

Figure 1: Pull-out curve of tire cord-reinforced $C R$ with various vulcanization temperatures for $30 \mathrm{~min}$.

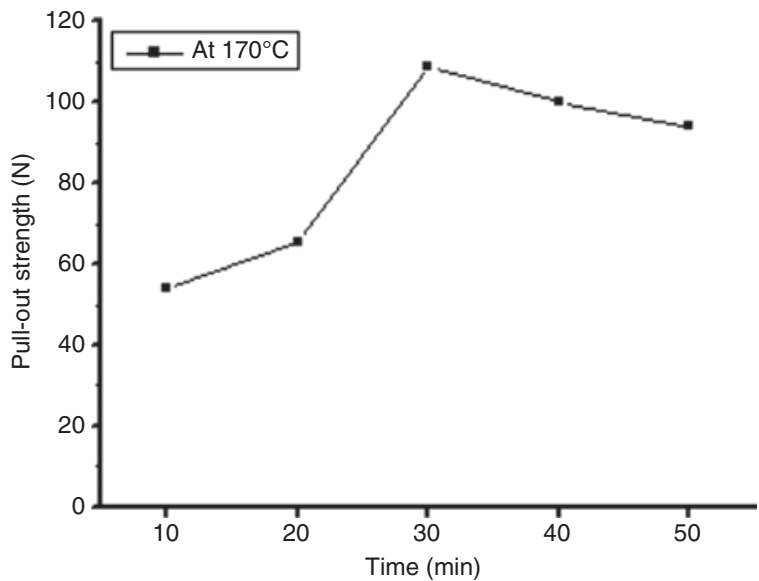

Figure 2: Pull-out curve of tire cord-reinforced $\mathrm{CR}$ at $170^{\circ} \mathrm{C}$ for various vulcanization durations.

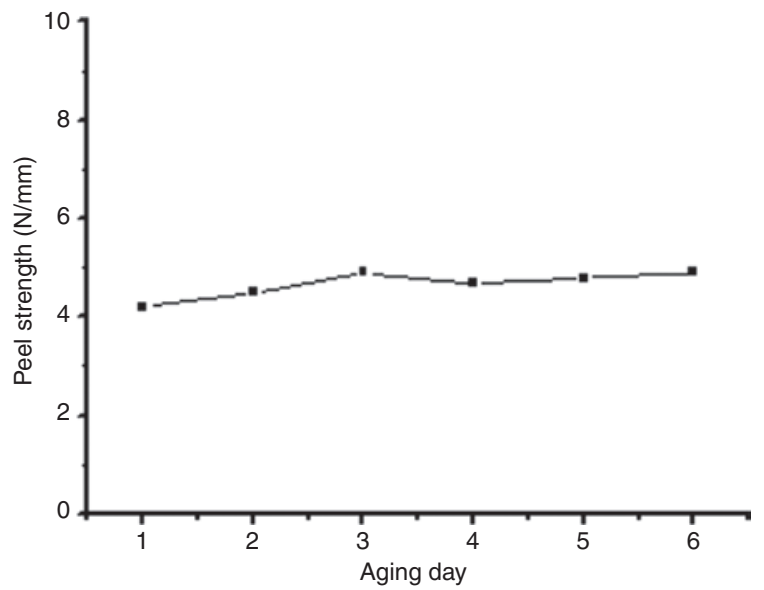

Figure 3: Peel strength between $\mathrm{CR}$ and polyester tire cord at $90^{\circ} \mathrm{C}$ for various aging durations.

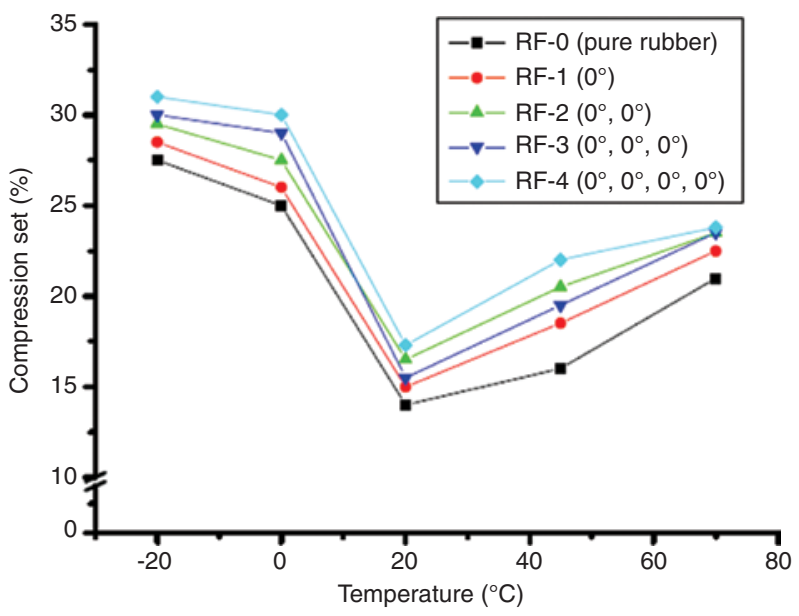

Figure 4: Compression set of $C R$ reinforced with different numbers of polyester tire cord layers at varied temperatures. 
possible reason is the increased cross-linking density of rubber after thermal aging $[13,14]$.

\subsection{Compression set}

Figure 4 shows the compression set of CR composites reinforced with different numbers of polyester tire cord layers at different temperatures. As can be seen, the compression deformation ratio for the RF-4 specimen is the largest

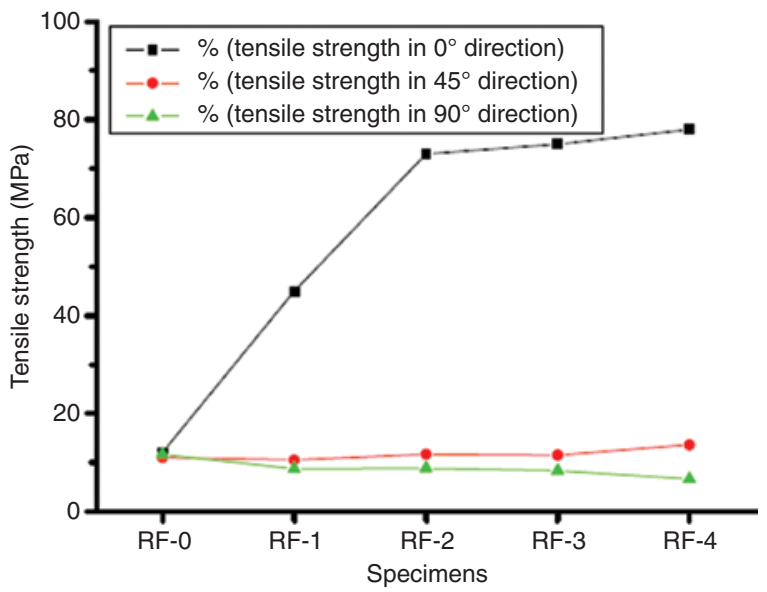

Figure 5: Tensile strength of $C R$ reinforced with different numbers of polyester tire cord layers at the $0^{\circ}, 45^{\circ}$, and $90^{\circ}$ directions.
(24.3\%), followed by those for RF-3 (24.0\%), RF-2 (23.8\%), RF-1 (23.0\%), and RF-0 (21.4\%). The unreinforced specimen (RF-0) exhibited full rubber elasticity; hence, the rubber remained highly elastic and did not easily deform upon release of compressive stress. As the number of tire cord layers increased, plastic deformation of CR composites occurred due to compressive stress. After the compressive stress is released, deformation occurred in the absence of effective resilience [15].

The results also show that the compression set is the largest for all specimens at high temperature. This can be attributed to the fact that when rubber is exposed to high temperatures, its molecular chains are softened, thus increasing deformation rates. When the specimens are at approximately $20^{\circ} \mathrm{C}$, the compression set value is at its lowest. The reason may be that tire cord-reinforced CR composites possess optimal rubber elasticity at $20^{\circ} \mathrm{C}$; thus, a compression set cannot be easily produced. At temperatures below $0^{\circ} \mathrm{C}$, the molecular chains of tire cordreinforced CR composites froze, and compressive stress increased the compression set value of the material.

\subsection{Mechanical properties}

Figure 5 shows the tensile strengths in the $0^{\circ}, 45^{\circ}$, and $90^{\circ}$ directions of $\mathrm{CR}$ composites reinforced with different
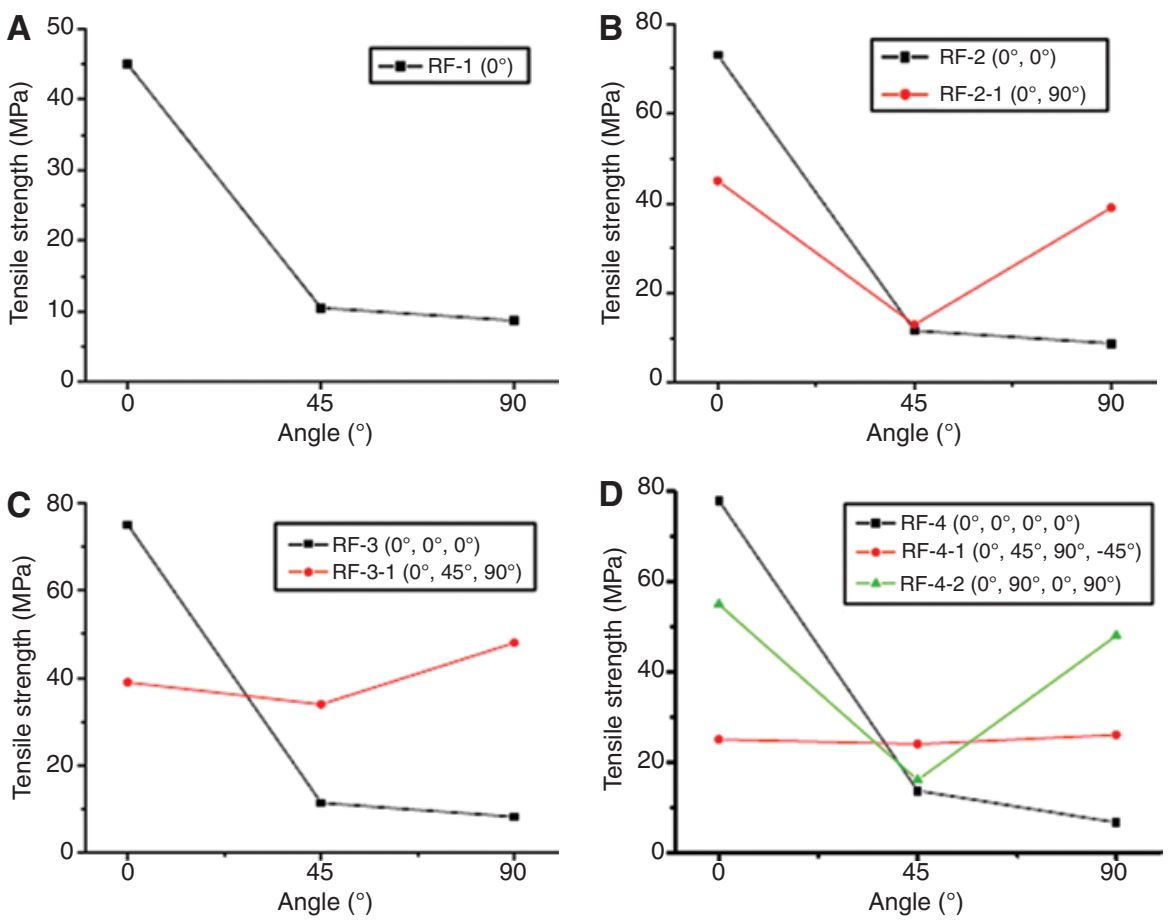

Figure 6: (A)-(D): Tensile strength at various angles of CR composites with different numbers of tire-cord layers and arrangement directions. 
numbers of polyester tire cord layers. The results show that when the angle between the tensile direction of the specimens and the tire cord reinforcement direction is $0^{\circ}$ (vertical), the tensile strength of the specimens increased as the number of tire cord layers increased. This is because the tire cord is the main object under stress.

Figure $6 \mathrm{~A}-\mathrm{D}$ show the tensile strengths at various angles of CR composites with different numbers of tire

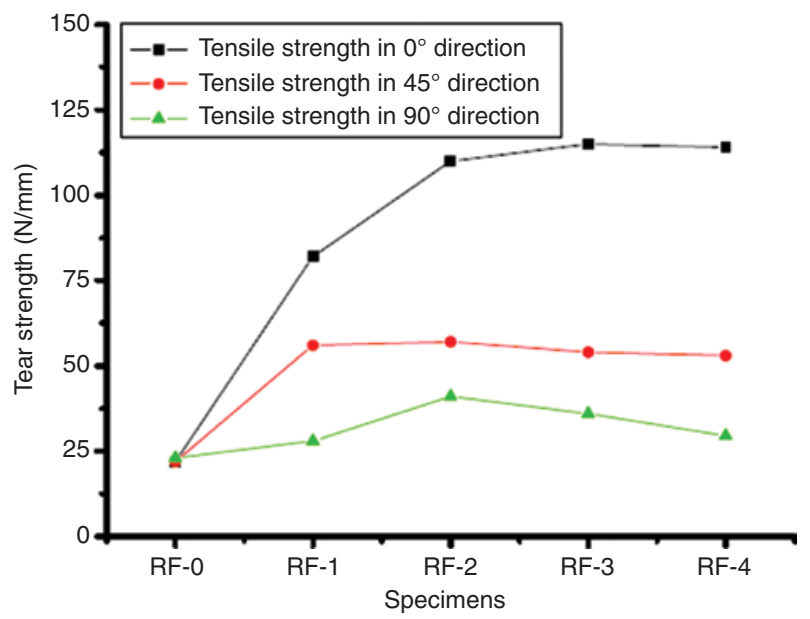

Figure 7: Tear strength of $C R$ reinforced with different numbers of polyester tire cord layers at the $0^{\circ}, 45^{\circ}$, and $90^{\circ}$ directions. cord layers and arrangement directions. As can be seen, when the tensile direction of the specimens and the alignment direction of the tire cord formed $45^{\circ}$ and $90^{\circ}$ angles, a tire-cord reinforcement effect could not be produced. This is because rubber is the main part under stress. Figures 6C-D show that when the tensile direction is parallel to the alignment direction of the tire cord, the specimens show excellent tensile strength, which increased with increasing number of tire cord layers.

Meanwhile, Figure 7 shows the tear strengths in the $0^{\circ}, 45^{\circ}$, and $90^{\circ}$ directions of $\mathrm{CR}$ composites reinforced with different numbers of polyester tire cord layers. The results are similar to those shown in Figure 5. Figure $8 \mathrm{~A}-\mathrm{D}$ show the tear strengths at various angles of $\mathrm{CR}$ composites with different numbers of tire cord layers and arrangement directions. As can be seen in Figure 8A, when the tensile direction is at $0^{\circ}$, the tear-strength value of RF-1 $\left(0^{\circ}\right)$ is optimal. The reason is that the alignment direction of the tire cord is parallel to the tensile direction. Figure $8 \mathrm{~B}$ shows that when the tensile directions are at $45^{\circ}$ and $90^{\circ}$, the tear strength of RF-2-1 $\left(0^{\circ}, 90^{\circ}\right)$ is greater than that of RF-2 $\left(0^{\circ}, 0^{\circ}\right)$. This is because for the RF-2-1 specimen, the alignment direction of the tire cord and the tensile direction crossed at $45^{\circ}$ and $90^{\circ}$ angles; therefore, tearing behavior like crack growth could not easily occur.
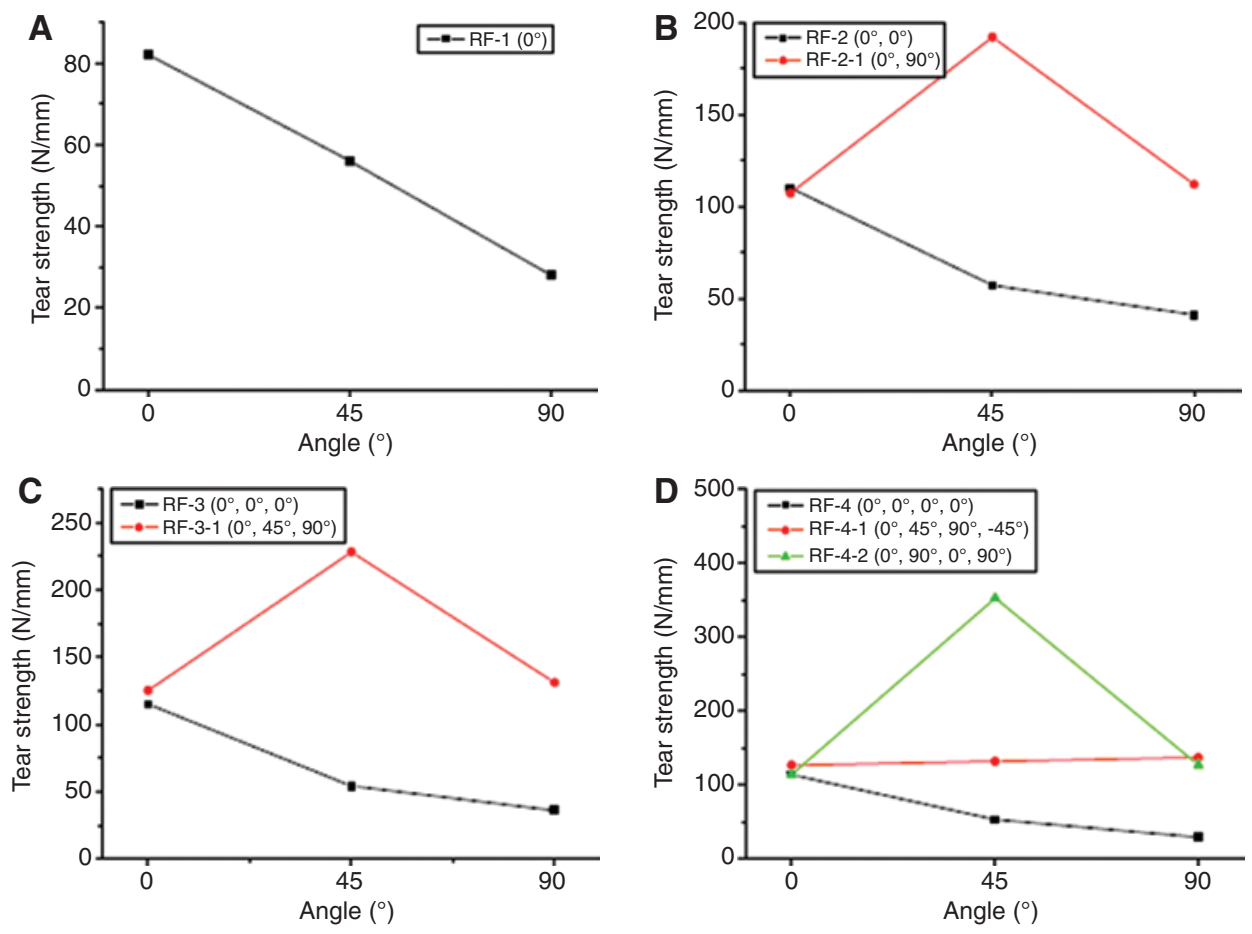

Figure 8: (A)-(D): Tear strength at various angles of CR composites with different numbers of tire cord layers and arrangement directions. 

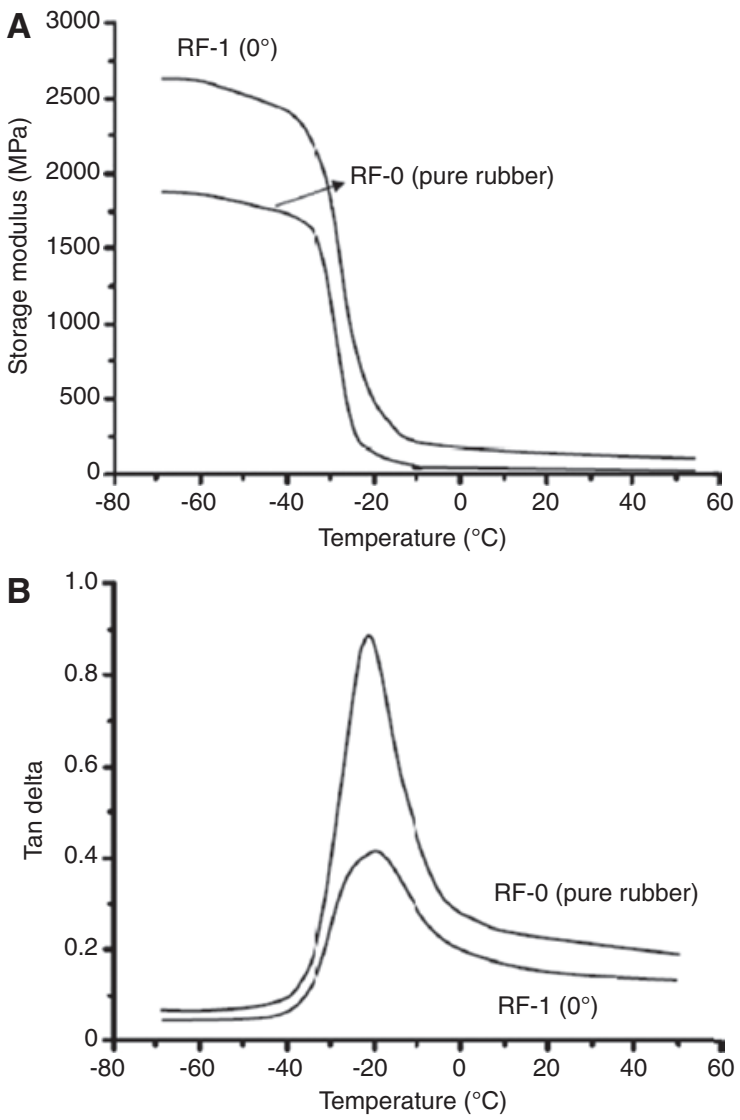

Figure 9: (A) Storage modulus and (B) tan delta vs. temperature plots for $C R$ reinforced with and without tire cord.

\subsection{Dynamic mechanical analysis}

Figure 9 shows the storage modulus and tan delta vs. temperature plots for CR composites reinforced with and without tire cord. As can be seen, at approximately $-70^{\circ} \mathrm{C}$, the storage modulus of the RF-1 specimen (2660 Mpa) is greater than that of the RF-0 specimen (1870 Mpa). Conversely, the tan delta value exhibited a decreasing trend. These results are in accordance with the findings of Ashida et al [16].

\subsection{Vibration isolation properties}

Figure 10 shows the dependence on frequency of the transmissibility ratio of CR composites with different numbers of tire cord layers. The related experimental data are summarized in Table 2. In the resonance region, the transmission ratio of RF-0 is the highest, followed by those of RF-1, RF-2, RF-3, and RF-4. The results suggest that using a great number of tire cord layers can significantly improve the

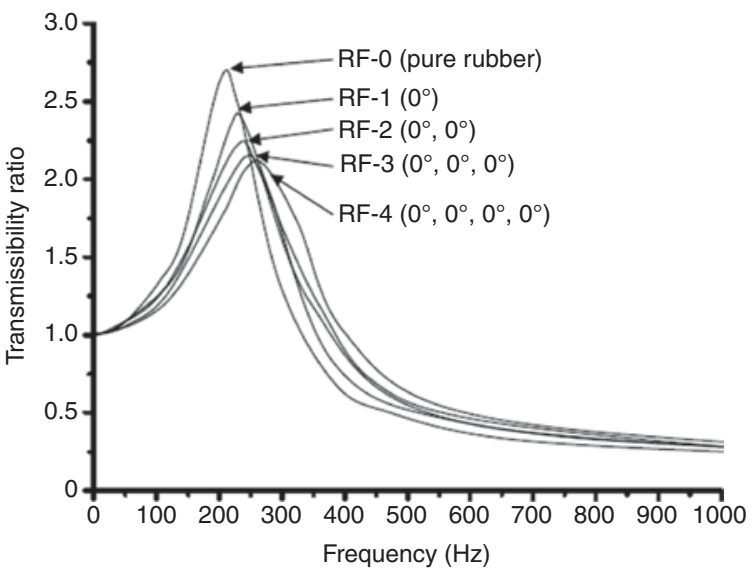

Figure 10: Dependence of transmissibility ratio of $C R$ composites with different number of tire cord layers on frequency.

Table 2: The effects of resonance frequency, damping ratio, and transmissibility ratio of $C R$ reinforced with a varying number of polyester tire cord layers.

\begin{tabular}{lrrr}
\hline Specimens & $\begin{array}{r}\text { Resonance } \\
\text { frequency (Hz) }\end{array}$ & $\begin{array}{r}\text { Damping } \\
\text { ratio }\end{array}$ & $\begin{array}{r}\text { Transmissibility } \\
\text { ratio }\end{array}$ \\
\hline RF-0 & 220 & 0.20 & 2.76 \\
RF-1 & 262 & 0.22 & 2.52 \\
RF-2 & 260 & 0.24 & 2.34 \\
RF-3 & 253 & 0.24 & 2.27 \\
RF-4 & 251 & 0.24 & 2.25 \\
\hline
\end{tabular}

vibration suppression effectiveness of the materials in the resonance region. In addition, the results indicate that when the number of tire cord layers increases, the resonance frequency of the material shifts toward higher frequencies. This can be attributed to the fact that the natural frequency of tire cord and the natural frequency of rubber influenced each other mutually when the tire cord content increased. Consequently, the natural frequency of CR composites shifted.

\section{Conclusions}

Specific conclusions can be made from the experimental results.

1. The permanent deformation of the tire cord-reinforced CR composites increased with increasing tire cord layers.

2. The optimal adhesive condition between tire cord and rubber is $170^{\circ} \mathrm{C}$ for $30 \mathrm{~min}$. An excessively high processing temperature or an excessively long processing duration reduces pull-out strength. 
3. The change of the alignment direction of tire cord and the number of tire cord layers considerably affected the tensile strength and tear strength of composites. When the tire cord reinforcement direction and tensile direction are identical, the tensile strength of the material is most significantly enhanced.

4. Regarding the dynamic mechanical analysis, the storage modulus value of the rubber is high at low temperatures after the rubber is reinforced with tire cord; however, the tan delta value decreased with increasing glass transition temperature.

5. Regarding vibration isolation properties, the transmission ratio of the tire cord-reinforced CR composites decreased with increasing number of tire cord layers. The results demonstrated that tire cord can significantly improve the vibration suppression effectiveness of the materials in the resonance region.

\section{References}

[1] Rath JP, Chaki TK, Khastgir D. J. Appl. Polym. Sci. 2012, 124, 266-274.
[2] Choi SS, Kim OB. J. Ind. Eng. Chem. 2013, 19, 650-654.

[3] Ismail H, Leong HC. Polym. Test. 2001, 20, 509-516.

[4] Aprem AS, Jose S, Thomas S, Barkoula NM, Kocsis JK. Eur. Polym. J. 2003, 39, 69-76.

[5] Martins AF, Meneses SM, Visconte LLY, Nunes RCR. J. Appl. Polym. Sci. 2004, 92, 2425-2430.

[6] Choi SS. J. Appl. Polym. Sci. 2002, 83, 2609-2616.

[7] Fulin C, Lan C, Caihong L. Polym. Composite 2007, 28, 667-673.

[8] Liao XX, Tan HS, Luo MC, Tang B, Liao SQ, Wei XD. Adv. Mater. Res. 2011, 239-242, 1601-1604.

[9] Das A, Costa FR, Wagenknecht U, Heinrich G. Eur. Polym. J. 2008, 44, 3456-3465.

[10] Thongpin C, Niltui P, Sornwaneenawakhun P, Maneeprom T, Malithong S, Wimolmala E. Adv. Mater. Res. 2010, 93-94, 631-634.

[11] Tsai PA, Wu JH. Sci. Eng. Compos. Mater. 2015, 22, 405-410.

[12] Steidel Jr RF. An Introduction to Mechanical Vibrations, 3rd ed., John Wiley \& Sons, Inc.: New Jersey, 1989.

[13] Zhang ZX, Li YN, Chen Q, Lu B, Xin Z, Kim JK. J. Vinyl. Additive. Tech. 2015, 21, 18-23.

[14] Choi S. J. Appl. Polym. Sci. 2002, 83, 2609-2616.

[15] Chiu HT, Tsai PA, Chen WY, Ger GS, Hwang WG. Chinese J. Mater. Sci. 1998, 30, 33-42.

[16] Ashida M, Oguchi, TN. J. Appl. Polym. Sci. 1985, 30, 1011-1021. 